\title{
The Exploration of the Food Education Program in Primary and Secondary Schools
}

\author{
Baosen Li, Dongya Zhang, Yucai Gao \\ Weifang Hansheng School of Shandong, Shandong, China
}

\begin{abstract}
Nowadays, unhealthy dietary habits, insufficient food knowledge, and lack of manual skills are typical issues among primary and secondary school students in China. To help students build up a strong constitution and life wisdom, Weifang Hansheng School of Shandong developed a food education course. This paper expounds on the course framework, contents of food education textbooks and the measures to implement the course.
\end{abstract}

Science Insights Education Frontiers 2021; 10(2):1461-1470.

Doi: 10.15354/sief.21.or070

How to Cite: Li, B., Zhang, D., \& Gao, Y. (2021). The exploration of the food education program in primary and secondary schools. Science Insights Education Frontiers, 10(2):1461-1470.

Keywords: Food Education Course, Food Knowledge, Healthy Diet, Food Nutrition, Dietary Habits

\footnotetext{
About Author: Dongya Zhang, Weifang Hansheng School of Shandong, Shandong, China. E-mail: 13854458620@163.com

Yucai Gao, Weifang Hansheng School of Shandong, Shandong, China. E-mail:2711429970@qq.com

Correspondence to: Baosen Li, Weifang Hansheng School of Shandong, Shandong, China. E-mail: 13465676572@163.com

Conflict of Interests: None.
}

() 2021 Insights Publisher. All rights reserved.

Creative Commons Non Commercial CC BY-NC: This article is distributed under the terms of the Creative Commons Attribution-NonCommercial 4.0 License (http://www.creativecommons.org/licenses/by-nc/4.0/) which permits non- 


\section{Introduction}

$\mathrm{F}$ IOOD education refers to the education of food and food-related knowledge for students from their early childhood, with extension of this education to the cultivation of students' outlook on life. Specifically, there are two components in this education. One is diet education on food nutrition and dietary habits; the other is value and ability education, to improve students' overall competence by engaging them in the process of food production, from farmland to table.

Since 1990s, food education has gained in popularity in many countries, where food education programs have been promoted through legislation, curriculum, and national campaigns. Japan promulgated the Basic Law on Food Education and the basic plan for promoting food education in 2005 , which has significantly helped the development of food related industries, improved the protection of traditional food culture, and increased the knowledge of some lifestyle-related diseases (Miyoshi et al., 2012). In the UK, education of food and agriculture were introduced into curriculum so that students can learn how to grow, process, and cook their own food in school (Ensaff et al., 2015). America witnessed in the last few decades a proliferation of garden-based nutrition-education programs for children and adolescents aiming at prompting healthy and balanced dietary habits (Robinson-O'brien et al., 2009).

In China, the idea of food education was first raised by Professor Li of China Agricultural University in 2006, who believed it necessary to promote food education in addition to moral, intellectual, and physical education given the public concerns with modern lifestyle-related diseases, food safety, food production, and environment (Li, 2010). However, at the level of the state, policymaking on food education is not at the top of the agenda; There are almost no food related courses or teaching materials for reference in the primary and secondary school curriculum (Zhu et al., 2019; Guo, 2020).

Weifang Hansheng School of Shandong started to develop a food education course in 2015. After six years of research and practice, it succeeded in creating the course to help students develop healthy eating habits and improve their practical ability. This paper elaborates on the framework of food education course, the design of twelveyear textbooks, and the implementation patterns.

\section{The Framework of the Food Education Course}

In September 2018, the school surveyed 1850 students on their dietary behavior and found that $82.7 \%$ of students like fried foods (such as KFC) and carbonated drinks while take in few vegetables, which leads to a general decline of students' constitution. The survey results also show that students lack dietary etiquette as well as labor skills (Chen, 2017). Findings of this survey indicate that food education should address not only students' dietary habits and nutrition balance, but also their overall dietary behavior including eating manners and food related knowledge learning.

\section{Objectives of the Food Education Course}


According to student development needs and existing problems, the school has set an overall objective of the food education course, that is, to help students build up a strong constitution and life wisdom. Specifically, it can be divided into general objectives and phased objectives.

\section{General Objectives}

Theoretical objective: Students acquire basic knowledge in food planting, food processing, and nutritional balance, and reach their own understanding of Chinese and Western food culture.

Practical objective: Students learn how to operate farming, prepare food, plan balanced menu, and other related skills. Each of them knows how to grow at least two crops and cook at least two kinds of food. In preparing food, they must pay attention to the sufficient inclusion of vegetables and be careful not to waste any ingredients.

Emotional objective: Students learn to respect workers and their work results and experience work enjoyment in practical activities.

\section{Phased Objectives}

First-phase objective: Students fulfil basic contents of the course (farming, cooking, healthy diet, table manners and food culture, etc.). They can skillfully use common dining tools and show good manners in dealing with food; they can briefly describe each activity and their reflections in their own words; They show respect to the work results of others by saving food.

Second-phase objective: Students can distinguish various foods, explain the nutritional composition of different foods, and present the benefits of good eating habits in their own words; They can fulfil tasks in farming, cooking and voluntary cooking to standards; They acquire abundant knowledge in dietary etiquette and food culture. Detailed reports are required to record the process of food education and the results.

\section{The Framework of the Food Education Course Based on its Objectives}

As shown in the framework (see Figure 1), aiming at "helping students build up a strong constitution and life wisdom", this course covers three dimensions (human and nature, human and society, human and self) and six topics (farming experience, cooking practice, voluntary cooking, dietary etiquette, healthy diet, food culture). The school attempts to fully realize the objectives of the course through the two implementation pathways (theoretical study and practical operation) and the two assessment methods (process assessment and final assessment).

Food culture sessions encompass food stories, regional dietary customs, food festivals, tea and alcohol history and cultural differences between China and the West. Healthy diet sessions cover food safety, dietary nutrition, eating habits, etc. Dietary eti- 


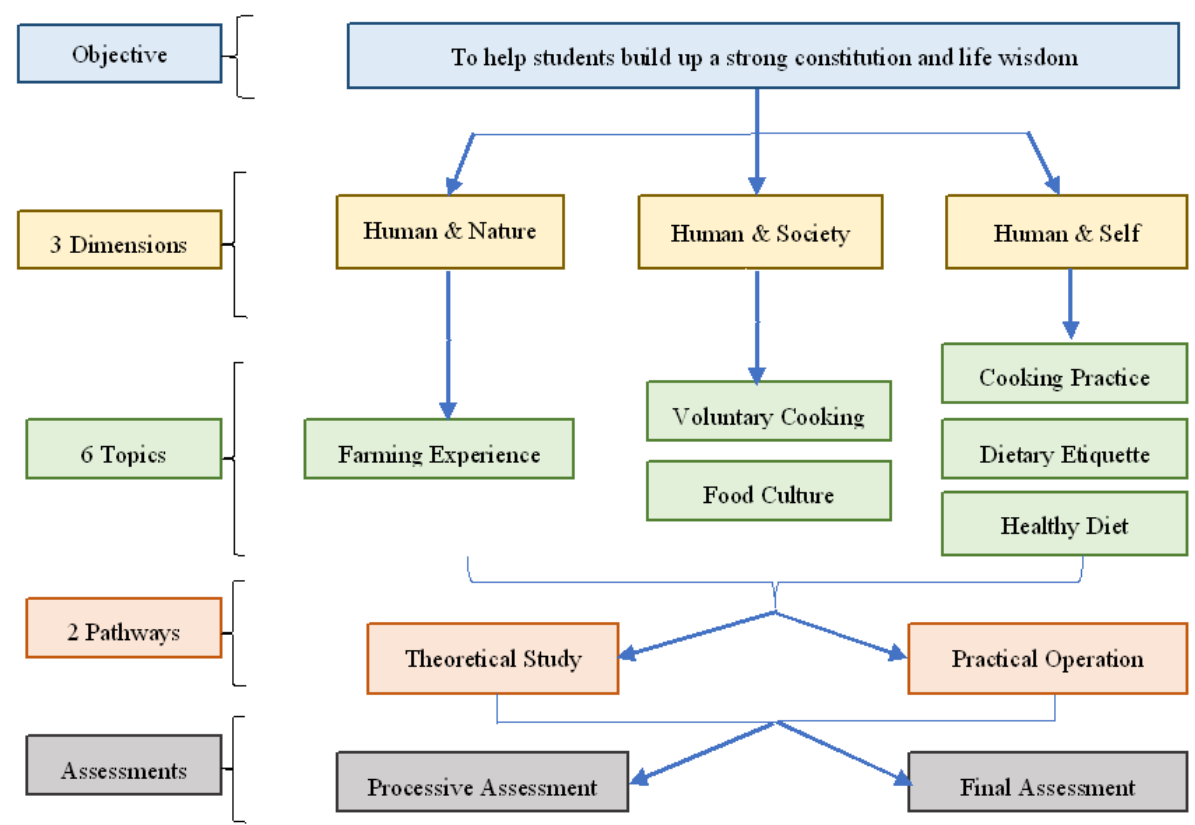

Figure 1. The Framework of the Food Education Course.

quette sessions deal with pre-meal preparation, dinnerware setting and table manners. Farming experience sessions include agricultural solar terms, farming tool operation, characteristics of crops, farming skills, soil improvement, agricultural science and technology. Cooking practice sessions includes ingredient identification and processing, food cooking, the use and maintenance of cooking ware, sanitation and cleaning. In voluntary cooking sessions, students take turns to help food education teachers with their full-time work (from 5 am. To 6 pm.) in the school kitchen.

The six segments of the course point to clear associations, to be specific, associations between farming experience and nature, between voluntary cooking and respect to physical work, between food culture and cultural understanding, between cooking practice and skill acquisition, between dietary etiquette and civilized manners, between healthy diet and eating habits.

\section{Food Education Textbooks}

The framework of the food education course is integrated with compulsory subject curriculum, life education, and labor education. Traditional culture such as solar terms, traditional festivals, food culture and farming culture is also incorporated into the food education course. After nine revisions, the school finally managed to compile a set of food education textbooks for students of 12 grades. The six topics in the framework run through the three stages of primary school, junior secondary school and senior second- 


\section{Table 1. Contents of the Food Education Textbook for Primary}

\section{Schools.}

\begin{tabular}{|c|c|c|}
\hline Grades & Chapters & Sections \\
\hline \multirow[t]{3}{*}{ Grade 1} & Chapter 1: Color elves in the Food Kingdom & \\
\hline & Chapter 2: Adventures in the Food Kingdom & \\
\hline & Chapter 3: Mobilization in Food Kingdom & \\
\hline \multirow[t]{8}{*}{ Grade 2} & Chapter 1: Food varieties & 1. Daily intake of whole grains \\
\hline & & 2. Daily intake of vegetables \\
\hline & & 3. Daily intake of fruit \\
\hline & Chapter 2: Little dieticians & 1. Food sanitation \\
\hline & & 2. Balanced diet \\
\hline & & 3. Wise eaters \\
\hline & Chapter 3: Dining rules & 1. Dining etiquette \\
\hline & & 2. Saving food with gratitude \\
\hline \multirow[t]{6}{*}{ Grade 3} & Chapter 1: Dietary habits & 1. Balanced menu without waste \\
\hline & & 2. Say no to junk food \\
\hline & Chapter 2: Self-reliance & 1. A decision maker at home and school \\
\hline & & 2. Gratitude to food providers \\
\hline & Chapter 3: Etiquette and culture & 1. Table manners \\
\hline & & 2. Art from food \\
\hline \multirow[t]{9}{*}{ Grades 4} & Chapter 1: Balanced nutrition & 1. My story of nutrition \\
\hline & & 2. My story of food \\
\hline & & 3. My story of sports \\
\hline & Chapter 2: Food safety & 1. Basic knowledge of food safety \\
\hline & & 2. Prevention of diseases \\
\hline & & 3. Harm of junk food \\
\hline & Chapter 3: Good dietary behavior & 1. Necessity of both meat and vegetables \\
\hline & & 2. Follow healthy eating habits \\
\hline & & 3. A decision maker of this week \\
\hline \multirow[t]{8}{*}{ Grade 5} & Chapter 1: Health from food & 1. Nutrients in food \\
\hline & & 2. A little dietician \\
\hline & Chapter 2: Good manners at table & 1. Chopsticks VS forks and knives \\
\hline & & 2. No leftover \\
\hline & & 3. Environment protectors \\
\hline & Chapter 3: Food-related festivals & 1. Dumplings, symbols of good fortune \\
\hline & & 2. Rice dumplings, symbols of reunion \\
\hline & & 3. Moon cakes, symbols of harmony \\
\hline \multirow[t]{8}{*}{ Chapter 6} & Chapter 1: Food guidelines for adolescents & 1. Food for adolescents \\
\hline & & 2. Inappropriate eating behaviors \\
\hline & & 3. How to build fitness \\
\hline & Chapter 2: Food and ecology & 1. Are they edible? \\
\hline & & 2. Growing plants \\
\hline & Chapter 3: Food culture appreciation & 1. Traditional Chinese food \\
\hline & & $\begin{array}{l}\text { 2. Comparison between Chinese and Western } \\
\text { food }\end{array}$ \\
\hline & & 3. Food culture all over the world \\
\hline
\end{tabular}


ary school and are emphasized in different ways in each stage. The first graders of the primary school are guided to obtain a preliminary understanding of food through stories from picture books; For the second to sixth graders of primary school, knowledge of common food and healthy dietary habits are emphasized; In Junior secondary school, the focus is on students' farming experience, dietary etiquette, and food culture knowledge; The senior secondary school students are required to focus on food processing and storage, food safety, and the comparison of Chinese and Western food culture. The following is contents of the food education textbook for primary schools (see Table 1).

\section{Integrative Implementation Patterns}

\section{School, Family, and Community Cooperation}

In the food education cooperation, the school plays a leading role as it can make the best of classroom teaching and guide on-campus and off-campus practice. Parents can serve as role models in educating their children on healthy diet and sound eating habits. To give full play to the role of parents, the parent school is set up to hold food education related activities for them. Parents are invited to participate in food festival, harvest festival and cooking festival alongside children. To combine community resources, five practice bases of food education are selected as locations for students to observe and practice food production in, and nutrition experts are invited to provide students with scientific nutrition education.

\section{Integration of Implementation Pathways}

Theoretical contents of food education: Each grade is provided with theoretical sessions in food education course. Through theoretical learning on the six topics (farming experience, cooking practice, voluntary cooking, dietary etiquette, healthy diet, food culture) in class, students fully understand the value, practical methods and dos and don'ts of the contents to ensure ideal results of practice.

Practical operation: All students take turns to undergo the practical sessions on the six topics of the food education course to enhance their living skills and build up wisdom in practice.

Emotional experience: Students achieve self-education and emotional sublimation through self-reflection and evaluation in theoretical and practical learning.

The food education course is conducted by integrating theory and practice and penetrated by emotional experience. The basic procedure is learning, practice, and expression, in which practice is led by theory, theory is proved by practice, and both enrich emotional experience.

\section{Multiple Locations for Food Education}




\section{Table 2. Assessment Records of Cooking Practice Sessions}

\begin{tabular}{|c|c|c|c|c|c|}
\hline $\begin{array}{l}\text { The first } \\
\text { level indexes }\end{array}$ & $\begin{array}{l}\text { The second } \\
\text { level indexes }\end{array}$ & $\begin{array}{l}\text { Assessment } \\
\text { standards }\end{array}$ & $\begin{array}{l}\text { Self- } \\
\text { assessment }\end{array}$ & $\begin{array}{l}\text { Group's } \\
\text { assessment }\end{array}$ & $\begin{array}{l}\text { Teachers' } \\
\text { assessment }\end{array}$ \\
\hline \multirow[t]{3}{*}{ Knowledge } & $\begin{array}{l}\text { Food } \\
\text { knowledge }\end{array}$ & $\begin{array}{l}6 \text { vegetables. } \\
\text { foods. } \\
\text { fole to categorize } \\
\text { tures of at least } 3 \text { kinds of } \\
\text { food. }\end{array}$ & & & \\
\hline & $\begin{array}{l}\text { Kitchen ware } \\
\text { knowledge }\end{array}$ & $\begin{array}{l}2 \text { kitchen tools. } \\
\text { istics of at least } 2 \text { kitchen } \\
\text { tools. } \\
\text { usage and dos and don'ts } \\
\text { of at least } 3 \text { kitchen tools. }\end{array}$ & & & \\
\hline & $\begin{array}{l}\text { Cooking } \\
\text { knowledge }\end{array}$ & $\begin{array}{l}2 \text { dishes. } \\
\text { ingredients of at least one } \\
\text { dish. } \\
\text { cooking method and cook- } \\
\text { ing steps of at least one } \\
\text { dish. }\end{array}$ & & & \\
\hline \multirow[t]{2}{*}{ Practice } & Cooking & $\begin{array}{l}5 \text { dishes. } \\
\text { ingredients of at least } 2 \\
\text { dishes. } \\
\text { the cooking of at least one } \\
\text { dish. }\end{array}$ & & & \\
\hline & $\begin{array}{l}\text { Putting } \\
\text { Kitchen } \\
\text { Items } \\
\text { in order }\end{array}$ & $\begin{array}{l}\text { after use. } \\
\text { en items. } \\
\text { em } \\
\text { top and clean the floor. }\end{array}$ & & & \\
\hline Reflection & $\begin{array}{l}\text { Awareness of } \\
\text { saving food }\end{array}$ & $\begin{array}{l}\text { cooking, eating up dishes } \\
\text { cooked in school kitchen. } \\
\text { dining, taking an appropri- } \\
\text { ate amount of food each } \\
\text { time. } \\
\text { importance of food, eating } \\
\text { up in each meal. }\end{array}$ & & & \\
\hline
\end{tabular}


Locations of food education include classroom, dining hall, farming base, restaurants, which means the farm is school, the dining hall is classroom, and dining is education. Professional cooking classrooms were built, and $3 \mathrm{mu}$ of ground plantation and $12 \mathrm{Mu}$ of roof planting area opened, to provide space for students to experience the whole process of seed selection, sowing, cultivating, harvest, cooking and sales.

\section{Multiple Subject Integration}

The school effectively integrates food education with subjects such as biology, geography, science, sports, Art, and morality \& the rule of law as well as with labor education and traditional culture education. Apart from one scheduled session every week, food education is incorporated into classroom teaching of other related subjects in terms of time investment. Moreover, the food education course relates to extracurriculum activities such as food festival, rice dumpling lesson at Dragon Boat Festival, winter solstice dumpling lesson, mid-autumn moon cake lesson, and other winter and summer vacation activities (for example, "being family CEO this week" and family civilization course).

\section{Multiple Assessment Forms}

The food education course emphasizes processive assessment. The final results include self-assessment (70\%), group's assessment (20\%), teachers' assessment (10\%). The assessment is carried out in three dimensions: Knowledge, practice, and reflection. Detailed assessment criteria are designed for each dimension, and results are graded in the number of (see Table 2.).

The implementation procedure of the food education course is presented as follows, using cooking practice sessions as an example.

(i) The Objective of Cooking Practice Sessions

Students can name the basic nutrients in at least five common foods and know how to cook them; During these sessions, they learn to cook at least one dish, create a new recipe, and make a new dish on this recipe for their family. Participation in group work is also required to cultivate students' teamwork spirit.

(ii) Procedure for cooking practice sessions

a. Kitchen Uniform

Under the teacher's guidance, the students dress themselves in kitchen uniforms and follow the order in the kitchen. The tutors help take photos of them.

b. Content Introduction

Food education teachers explain the main content and operation of this class, and let students watch the video of cooking practice.

c. Cooking Practice

Students practice cooking in groups according to the steps shown in the video.

d. Food Sampling

The prepared dishes are photographed with the "cooks". No scrambling is allowed in sampling the food. 
e. $\quad$ Cleaning $U p$

Uniforms should be stacked and placed as required; Kitchen ware should be cleaned and put away and the worktop and ground cleaned.

f. $\quad$ Result Checking

The teacher checks on the whole process, keep records and report to the supervisor of the grade in time.

(iii) Assessment

Processive assessment is used to assess students' performance in cooking practice. The results include self-assessment (70\%), group's assessment (20\%), teachers' assessment (10\%).

\section{The Outcomes of Food Education in Weifang Hansheng School}

In the 6-year practice, the food education program has proved to be significantly effective in improving students' food knowledge and dietary behavior. Students' dietary habits become healthier and their constitution stronger. The rate of breakfast skipping is lowered from $29.4 \%$ to $1.7 \%$; The number of students with food fussiness decreases by 28.6\%; Students show willingness to give up junk food and carbonated drinks. Moreover, students' dietary manners have improved remarkably, which is reflected in their increased awareness of queuing up to take meals, keeping quiet when eating, and taking appropriate amounts of food to avoid waste.

In addition, the school has built a professional team of food education staff. They have been well motivated by the school culture of curriculum research and creation in developing the food education course.

The joint efforts of students and teachers in the development of the food education course have helped raise the school's profile. Numerous media have conducted exclusive interviews and special reports on the food education program of our school, and a total of 16 schools in Yunnan, Jiangsu and Shandong Province have referenced the implementation patterns of the school's food education course. The school took part in research on key issues of national nutrition and food security, one of the key projects of the Chinese Academy of Sciences and became a national base of food nutrition education. It was invited to participate in National Campus Meals Conference, China education science forum and China green agriculture and food nutrition summit forum. All the academic involvement help spread the school's experience in food education and motivate the school to strengthen its research and development in this field. 
Li et al. (China). Food Education Program in Primary and Secondary Schools.

\section{References}

Chen, G.F. (2017). The status quo and cultivation of rural primary and secondary school students' labor awareness. Sichuan Education, 2017(11):22.

Ensaff, H., Canavon, C., Crawford, R., \& Barker, M.E. (2015). A qualitative study of a food intervention in a primary school: Pupils as agents of change. Appetite, 95:455-465. DOI: https://doi.org/10.1016/j.appet.2015.08.001

Guo, Y.H. (2020). The demand for and practice of labor education in primary and secondary schools. Education Science Forum, 2020(20):52-55.

Li, L.T. (2010). A new subject of national quality education: Food education. Agricultural Product Processing (Innovation Edition), 2010(5):4-6.

Miyoshi, M., Tsuboyama-Kasaoka, N., \& Nishi, N. (2012). School-based "shokuiku" pro- gram in Japan: Application to nutrition education in Asian countries. Asia Pacific Journal of Clinical Nutrition, 21(1):159-162.

DOI:

https://doi.org/10.3316/ielapa.005020511473 $\underline{466}$

Robinson-O’Brien, R., Story, M., \& Heim, S. (2009). Impact of garden-based youth nutrition intervention programs: A review. Journal of the American Dietetic Association, 109(2):273-280. DOI:

https://doi.org/10.1016/j.jada.2008.10.051

Zhu, Q., Li, F., \& Wang, J.Q. (2019). A comparative study on the contents of food education in primary schools in the United States and Japan. Primary and Secondary Schooling Abroad, 2019(2):21-26. 